\section{ON THE TREATMENT OF ULCERS OF THE LEG WITHOUT REST.}

By Thomas Huxt, Fsq., F.R.C.S., Surgeon to the Western I)ispensary for Diseases of the Skin.

[Rcad before the Medical Society of I.ondon, Dec. 13th, 1856.]

THE ulcers of which I am about to speak, are chiefly confined to the labouring ciasses. They are by far the most frequently met with in women, and still more commonly in those who have borne children. They are, for the most part, disposed to heal when the patient is confined to the recumbent posture, the wounds being treated with simple dressing. Hence, with a few rare exeeptions, tijese cases recover sooner or later under hospital treatment; but as soon as the patient is discharged, and again pursucs her daily toil, especially if she be a laundress, or otherwise occupied in a standing posture, the wound breaks out afresh, and is seldom healed until she re-enters the hospital, or otherwise obtains rest in the horizontal posture.

In this way, thousands of poor women in this country, as well as many hundreds of poor men, are rendered compara tively useless to their families, and often reduced to extreme poverty and distress, spending half their days in crippled help lessness, and often suffering great pain, which, by destroyin the rest at night, lreaks down the health. Much misery and destitution would doulstless be prevented if a method could be devised of healing these ulcers while the patient is allowed the free use of the lower limbs. That this may generally be accomplished, I have had ample practical proof; and my object in this communication is not to introduce any new method of treatment, but rather to shew why the established and approved methods so frequently fail.

But it will be necessary first that I should define the cha. racter of the ulcers to which $I$ allude.

The lower extremity is subject to three linds of ulcer-the strumous, the syphilitic, and the venous or varicose. There are other kinds, but they are far less commun. The strumous ulcer occurs frequently in children and young persons: rarely in the mature or aged. Its character is that of suppurative inflammation, terminating in a languid looking sore on a livid ground, frequently presenting tumid and flabby granulations. The syphilitic ulcer of the leg is always secondary or tertiary, and will break out afresh years after all suspicion of the infection of lnes has gone ly. It is a deep irregular sore, surrounded by a reddish brown blush, and often burrowing under the dermis, sometimes leaving between two sores a band or bridge of copper-coloured integument, which overlies a slough. Mercury is the remedy for this kind of sore; and cod-liver oil is the best remedy for the strumous sore. But I merely allude to these specific ulcers in order that I may not be supposed to confound them with, or include them in, my description of the chronic venous, or varicose ulcer of the leg. This latter is a purely local affection, and depends in every instance upon some interruption in the venous circulation. From some imperfection or inaction of the valres, the venous blood is thrown back upon the capillaries, the nutrient process is vitiated, and an ulcer results. The varicose state of the veins is often seen in the prodigious distension and serpentine course and thickened investments of the external veins of the leg, and sometimes of the thigh. In other cases, it is not observable externally; but the disease still appears to arise from interrupted circulation, probably in the deep-seated veins. The ulcer may vary a good deal (in different cases) in extent, in depth, and in character. It may be as small as a split-pea, or it may extend all round the leg, or even occupy one-half or three-fourths of the entire limb: it may be superficial and cutaneous, or it may extend to the bone: it may be phagedenic and gangrenous, or inflammatory and irritable, or indolent and stationary; but it is always deficient in granulations, and more or less unhealthy. It is frequently surrounded by a feeble or disorganised dermis, assuming the form of a scaly, papular, erythematous, or vesicular eruption; or the limb may in one case be wasted and scarred; in another, swollen, hypertrophied, or odematous; and in a third, the cellular membrane may be infiltrated with adhesive exulation, and the joint more or less anchylosed. The constitutional disturbance varies with the character of the ulcer. The system is often severely affected when there is active phagredena or an extensive destruction of parts; or when, as often happens, the pain is so severe as to disturb or destroy he patient's rest: but, in the majority of cases, the general health is very good, and the disease has the character of a local affection arising from local causes. Indeed, many patients believe that the ulcer is salutary, and that it could not be healed without the risk of damage to the general health. And it is well if the practitioner does not in some degree sanction, silently or otherwise, this unfounded, and now nearly obsolete prejudice.

Constitutional Treatment. When the ulcer is connected with well marked disease of the surrounding skin, the case may require alterative treatment; and if acute inflammation be present, leeches and purgatives; when it is sloughy or gangrenous, tonics and stimulants may be necessary; but when the health is good, and there is no strumous or syphilitic taint, internal medical treatment is rarely required for the healing of the sore, although purgatives may be necessary afterwards; and if the discharge has been copious, and the ulcer of long standing, it is a safe and useful plan to accompany the surgical treatment with a course of moderately active purgatives or diuretics.

Surgical Treatment. I may assume that the Fellows of the society are all well acquainted with the plans of treatment proposed severally by Messrs. Whately, Baynton, Scott, Spender and many other writers of more recent date. These are all founded on the simple principle of giving due artiticial support to the limb, by the application of plaster or bandages; the practice of each differing only in unimportant details-MIr Whately dressing the ulcers with pledgets of cerate; $\mathrm{Mr}$. Bayn ton and Mr. Scott using adhesive plaster; and Mr. Spender chall dressing. In the hands of all these surgeons, I do not hesitate to say that equable pressure is the chief agent in the cure; and the extraordinary success attending the practice of each one consisted mainly in the skill and adroitness, attained only by long practice, in applying the bandage or plaster so as to make it press equally on every portion of the irregular surface of the limb. The usual hospital practice is the same in principle. The German poultice is a convenient dressing; and while by the recumbent posture the vessels are reliered of the distension occasioned by the gravitating fiuids, the atmospheric pressure on the limb itself forms a sufficiently powerful, as well as an elastic bandage, affording a constant and equable pressure on every portion of the surface. It is not necessary that I should comment on the very ingenious device introduced by our intelligent associate, Mr. Gay, consisting of an incision into the integuments surrounding the ulcer, where the healing process is prevented by the tight and contracted condition of the neighbouring shin. To this I Jave no objection to offer; but it does not apply to the great majority of cases under consideration, if, indeed, to any of them.

Modern surgery, therefore, is competent to the treatment of ulcerative diseases of the leg. There is, I believe, no essential defect in it, no necessity for anvthing new. Why then is it so notoriously unsuccessful? Mainly because the application of a bandage is looked upon as an easy and simple operation, which may safely be intrusted to the patient, the nurse, or the dresser; whereas I know of few operations in surcrery more difficult to perform, or requiring more painstaking practice than the appiication of a bandage to the human leg in such a manner as that every portion of the limb, from the toes to the knees (including especially the hollow between the heel and the inner and outer malleo!us) shall receive equal and abiding support. In the careless manner in which a bandage is com monly applied, it often does more harm than gool. If it be at all tighter round the leg, for instance, than rounil the foot, the foot and ankle will become swollen and odematious; and on removing the bandage there will be seen deep fissures where one edge of the bandage has been unduly tight, and a puffiness in other parts, which adds to the interruption of the circula tion. And it is extremely difficult wholly to avoid this unequal pressure. There are also other impediments to success; and at the risk of being tediously minute, I must beg attention to several important details.

First, the dressing of the ulcer is a point of little mo ment as regards the ultimate success of the bandage; but cime will be gained by a proper dressing, the treatment will be more speedily successful, and the patient will liave much less to suffer. Certainly there is no dressing which leserves the name of a panacea. 'The appearance of the ulces, not very easily described, always suggests to the practised eye what will best suit it.

Offensive ulcers, especially if they are disposed to gangrene, are easily and readily convertible into healthy sores, by simply flling them with a powder consisting of equal parts of finely pulverised vegetalile charcoal and prepared chalk. Over this a poultice may be applied if the sore be very irritable; but it is 
generally sufficient to apply over the charcoal a piece of dry lint and bandage. On dressing it the next day, the wound is seldom offensive; and on the third or fourth day, if the patient's health be duly attended to, it is commonly converted into a healthy looking sore.

Very painful and irritable ulcers, disinclined to heal, I usually dress with a dossil of lint dipped in chloric ether, and then apply the bandage. This gives severe pain for a few minutes, but the patient will get a good night's rest, and never objects to its repetition.

Sanious ulcers, having no defined edge or depth, require a free application of nitrate of silver or a solution of sulphate of copper, as also do those sores in which the granulations are excessive.

Sluggish ulcers, covered with a tenacious yellow coat of muco-pus, are often roused into healthy action by the application of a little finely powdered nitric oxide of mercury, or an ointment of the same material-two drachms to the ounce.

Ulcers with hardened cartilaginous edges require severe pressure. A dossil of dry lint should be applied to the surface of the sore, and then the edges of the ulcer should be very tiglitly drawn together with strips of adhesive plaster; over this should be laid a yiece of tow or wadding, and the whole supported by a flamnel bandage applied as tightly as possible. Under this treatment, the absorbents are awakened into activity, and the sore becomes very manageable.

Sorcs of the more ordinary character I generally fill with dossils of soft dry lint, placing over this a pledget of spermaceti ointment, and a bandage applied with gradually increasing tightness, i.e., more and more tightly every dav.

All these ulcers require daily dressing for the first fortnight or more, until the discharge has nearly ceased; and then fortyeight hours may be allowed to elapse between each dressing. As the granulations arise, they sometimes require a touch with the sulphate of copper, or lint dissolved in the solution.

Bundarirs. Calico and linen bandages are generally inefficient, and often useless. They do not yield sufficiently to the motion of the limb; consequently, they cut the leg on one edge, and become louse on the other. The elastic cotton handage sold at the shops is a very stupid affair. The two edges are stitched together, and form a cord, which cuts the leg if the bandlage is tightly applied ; and, if not tightly applied, it is useless. If the ulcer is disinclined to heal, a famnel bandage is essential to its permanent cure. This bandage shonld be made of moderately fine Welsh flannel, from seven to eight yardis long, according to the size of the limb, without a single joining, and exactly two and a half inches wide. The flannel should not be coarse, for then it is too rigid and rough for the tender skin; neither should it be very fine, otherwise it will fall into folds or become loose. If the breadth be more than two and a half inches, it is impossible that it should lie smoothly about the foot; if less than two and a half inches, the portion enveloping the calf will slip out of place as the patient walks. But, as the flannel shrinks in washing, if the patient have a large leg, two and three-fuarter inches may be allowed for new and unwashed flannel to commence with. So long as there is any clischarge from the wound, it will be recessary to have a clean bandage daily. The patient should therefore be supplied with two bandages, and be admonished not to have them washed in very hot water, as they will shrink, and become thick and unyielding.

Application of the bandage. Before applying the bandage, it should be rolled up very tightly and evenly, otherwise it will slip on being applied. The wound being dressed, the patient should sit in one chair, and place the heel on the corner of another chair, so as to give room to apply the bandage to the heel. The first turn or two should be taken round the foot close to the little toe, taking care that every turn is even, so that one edge of the flannel ioes not cut while the other is loose. The next turn should be round the ankle, just as far from the heel as is requisite to lay the bandage even and tight; next round the foot again, nearer the heel than before; then round the point of the heel, and over the instep; then under the foot, and, slantingly inclosing the hollow of the inner malleolus, it should be brought again round the leg, and afterwards round the hollow of the outer malleolus; then round the point of the heel a second time, and round the font a fourth time; then round the leg, and carried spirally over the calf up to the knec, allowing the bandage to take a turn on itself just as often as it fails to lie even and flat without such a turn. Care should be taken that the bandage is rather tighter round the font and instep than round the small of the leg and calf. The bandage should reach to the knee, where it should be pinned, not tied, and the stocking should be pulled over it, no garter being allowed on any account. If the patient complains that the bandage cuts any where, it should be taken off, and reapplied with additional care. It is very often requisite to apply a compress of tow or cotton wadding to the hollow of the ankle, to secure sufficient pressure there, especially if that be the seat of the ulcer, which often happens.

In the method of applying the bandage recommended in books on surgery, and even by Whately himself, this part is left altogether unsupported, and the pressure is applied to every part of the leg except where it is most wanted. It requires some practice to adjust this matter nicely without putting too many folds round the foot; but it may be done, and is worth the trouble, inasmuch as without it we may fuil.

The advantage of a flannel bandage over a cotton one is threefold. First, it is a bad conductor of heat, so that the wound is preserved in a uniform temperature. This is very important. Frequent changes of temperature present a great impediment to granulation. Mr. Crompton of Manchester has shown that the great advantage of dressing burns and scalds with flour, wadding, or wool, consists not in excluding the air, as is commonly supposed, but in preserving an equable temperature. 'Thus I have found ulcers of the leg, in cold weather heal rapidly under a flannel bandage, which refused to heal under a cotton one. Another advantage of flannel is, that it yields a little (not too much) to the motion of the leg. I have had patients who have walked miles to be dressed, without complaining, with a flannel bandage, who could not endure the pain of standing in a cotton one. Thirdly, the flannel, having a rough surface, adheres to its own folds, and does not slip down the leg. A well applied flannel bandage will keep its place a week, night and day. A cotton or calico bandage will scarcely remain in place an bour.

Covering the whole foot and leg with adhesive plaster, as recommended by Mr. Baynton, and practised by Mr. Scott, is open to many objections. 1. Unless it be removed daily, it confines the discharge too much, whereas this readily escapes through the pores of the flannel. 2. As it requires daily removal, it is apt to irritate the skin, often already irritable from disease; and, in male subjects, it adheres painfully to the hair on the legs. 3. It confines the muscles too much, and is a great hindrance in walking. When wounds require adhesive plaster, two or three small strips are sufficient with a bandage. 4. It is expensive and troublesome, and is much missed when the patient leaves it off. Notwithstanding these objections, it succeeded marvellously in the hands of MIessrs. Baynton and Scott.

It often happens that, on the first application of the bandage, the leg becomes more painfnl, the discharge from the wound more copious, and the wound looks irritable and foul. This is particularly the case where the limb is cedematous, and the fluid is forced through the wound; but the second or third dressing finds the swelling reduced, the wound less painful and disposed to heal. It is very important that the bandage be applied in the early part of the day.

It has been proposed to relieve the venous pressure which originates these ulcers by cutting out the portion of the vein containing the diseased valves. This is very uncertain in its results, and by no means a safe operation. A better plan is to bind a small piece of nitrate of silver on the vein; but I have reason to believe that, as the varicose veins often disappear after the bandage has been worn for a few months, the valves recover themselves, and resume their proper office, without any operation for their destruction.

When an ulcer is situated on the sharp edge of the tibia, just on the shin, a tight bandage is not admissible; but a piece of spongio-piline or wadding may be placed on the sore, and a well adjusted bandage applied loosely over it.

Under the careful management now described, a very large majority of ulcerated leos may be soundly healed, even while the patient is pursting his or her ordinary arocation; and I have frequently succeeded with patients in the country who actually walked six or cight miles to be dressed, and then walked back again. There are a few cases, however, in which I have been obliged to insist upon the latient resting for the first week or two; but if the sore be thus healed, it irvariably breaks out again, and does not prove to be soundly cured, whereas but few of the patients who are allowed to walk ever return for after treatment.

This is one of a fer neglected suljects in which, at the present moment, the profession is most deeply interested. This branch of practice is known to be very much monopolised 
by old women and quacks; and we are apt to forget, in our zeal for medical reform, and amidst our earnest appeals to the legislature for a legal separation between the qualified and unqualified practitioner, that quackery thrives as easily on our own neglects as on the ignorance of the public; and that there are public men who know how to throw this in our teeth. So long as there are certain classes of disease which are thought unworthy of the attention of the hospital teacher and college examiner, so long will the profession itself prepare a fruitful soil in which quackery will grow and thrive. And my object on this occasion has been, not to discuss the comparative merits of different kinds of ointment, plasters, dressings, and other minor details, but to exhibit in a disencumbered form the principle on which all practical men agree-that of giving firm, and constant, and equable support to the whole surface of the limb, from the toes to the knee. If this principle were universally understood and carefully acted out, we should hear of no more incurable bad legs healed by Holloway's ointment -no more amputations for mere ulceration-no more ankylosed joints from mere inaction of the joint induced by the tenderness of the skin or the presence of an old and irritable ulcer.

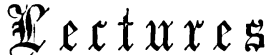 \\ ON CERTAIN VIEWS ON THE NATURE AND TREATMENT OF PHTHISIS BY PHYSICIANS.}

\author{
DELIVERED AT THE \\ BROMPTON HOSPITAL FOI CONSUMPTION AND DISEASES OF \\ THE CHEST, IN THE SUMMER OF 1856.
}

By Edward Smith, M.D., LL.B., B.A., Licentiate of the Royal College of Physicians; Assistant-Physician to the Hospital, etc.

LECTURE $I$.

BASES OF MIEDICAL KNOWLEDGE. TUBERCLE IN THE LUNGS IS NOT ESSENTIALIY DUE TO THE SCROFULOUS DIATHESIS, BLOODDISEASE, OR HEREDITARY INFLUENCES. RESEARCHES AS TO THE QUANTITY OF THE INGESTA AND EGESTA, SHOWING THAT PHTHISIS IS NOT ESSENTLALLY DUE TO DEFICIENCY OF FOOD, DEFECT IN DIGESTION, OR WASTE OF FOOD.

All the linowledge which the medical profession possesses must be based upon demonstration, personal experience, or reasoning. The second, conjoined more or less with the third, constitutes what is known by the term authority, and acquires its value in our judgment from some supposed or real superiority in the author, as to the extent of his field of observation, or his habits and power of observation and reflection. Of these two bases, viz., demonstration and authority, this age has exhibited a decided preference for the former; and it is evidert that a demonstration must be more conclusive than an assertion. The ouly objection that can be raised, is the liability to error which must ever exist in all the inquiries which are required to constitute demonstration; and hence even a demonstration may be held to be truth in one age and falsehood in another. But in how much higher a degree must authority be exposed to error, when men are so liable to be deceived by the imperfection of their senses and the appliances employed to aid the senses, by the prevalent opinions of their day, by the imperfection of their judgment, and by the uncontrollable influences of prejudice. And such sources of fallacy are apt to be more open at a late period of life; that is, at the period when authority is naturally claimed and allowed. Hence authority in general knowledge during the middle ages, and in medical knowledge in the persons of Hippocrates and Galen, at first gave stability to knowledge, and then fixedness to error: and so it must ever be. With the increase of medical knowledge during the last two centuries, and particularly in our own time, authorities have vastly multiplied, and each has held the sceptre for a limited period, with the result of losing it in all, and of regaining it in a few instances. Thus our pro fession is continually changing its so called truths; and in a few instances, as that of the doctrine of the humoralists, this continued movement has completed its circle, and has returned to the point whence it started centuries ago.

In a profession which is so much based upon personal knowledge, there must always be a deference paid to authority; and those who have few opportunities and small powers of obtaining truth must be content to sit at the feet of others; but it would be only in accord with the spirit of the times if they ever looked with some degree of dissatisfaction upon authority, and de manded demonstration. Whilst, therefore, I hold the opinions of the many eminent men of this day in the greatest esteem, I she' not be thought presumptuous if I ask for their facts and weigh their arguments; and if, by the aid of demonstrative inquiry, I should vary the opinions which now prevail. As it is the inherent right of a man to use well his mental powers, and to cherish freedom of thought, so it is the right of our profession to multiply its points of inquiry after truth, and to avoid rather than seek for the shackles of mere authority. Our profession, and especially that department of it with which we are here more particularly engaged, is likely to add to its influence for the good of mankind, as it permits and gives due weight to both demonstration and authority, looking, however, to the latter as a fertile source of false theories, and the former of false facts.

I have for some time been closely engaged in inquiries of a demonstrative character in reference to phthisis, and have obtained facts and opinions which to my own mind have called for a modification in the received view of the nature of that dis ease. To authority I do not appeal; but I venture to hope that the facts which the inquiries have elicited may be received as a sufficient ground for the opinions which I shall now veuture to bring forward.

On inquiring into the nature of phthisis, we can seize upon two circumstances, viz. :-lst. The morbid condition which it leaves behind it; and $2 \mathrm{nd}$. The changes in the working of the system which attend it. The former has of late years been more particularly brought under notice, probably on account of the constancy with which tubercle is found associated with it in the lung, and the readiness with which its appearance, at least so far as the naked eye may guide us, is recognised. Thus tubercle has been elevated to the dignity of the essential pa: $i$ of phthisis, without our having agreed as to what it is, whence it is derived, or how it is deposited in the lung as we find it. Now, it must be evident that this tubercle is the effect of ariterior conditions, and consequently an effect instead of, or in addition to its being, a cause; and if that may be admitted, it is equally clear that it may be an accident, and not an essence; and that the condition of the system or the organ in which it is produced, is that to which attention is primarily due, and which may prove phthisis to be one manifestation of a state which, with equal readiness, may exhibit, under other circumstances, other evidences and other so called separate diseases. To regard the tubercle as the essence is to limit greatly the range of our observation: but to look upon it as an effect or an accident, opens a wide field for study and investigation.

If we start, then, from this point, we may search for its cause either in the immediate spot in which it is found, and thus regard it as a local disease, and a general disease only so far as every part must be influenced by the general system; or we may consider it as proceeding essentially from a general cause, and found locally only so far as every entity must have a location. We will now enter on this part of the discussion.

It is abundantly evident that the disease has a local habitation in the lung, and also that, as it progresses, the system in general exhibits many conditions opposed to those of health; but it would not thence follow that the tubercle resulted from any state of the general health, but rather that the increasingly diseased condition of the general system resulted from the deposit of the tubercle and the interference which it must effect in the action of an organ so essential to bealth; or, perhaps more likely still, from a condition which may have been anterior to and causative of both.

Now, there is much to support these latter views of the disease; for so little is the general system affected in the earliest moments of the deposition, that of common agreement we affirm that the exact period of first deposit cannot in any case be determined with certainty. Nay, so insidious is its march, even locally, and so gently are its effects there and upon the general system developed, that we often find the deposit most abundant, and the destruction of the organ considerable, when the patient's own attention is first called to it. Surely this is far opposed to any theory which would attribute the deposition 